\section{IN brief}

\section{Avastin as good as Lucentis}

One-year results from the first head-to-head study of Genentech's VEGF-binding monoclonal antibody (mAb) Avastin (bevacizumab) show it is as effective in treating neovascular age-related macular degeneration (AMD) as Genentech's much more expensive Lucentis (ranibizumab). For years, Avastin, a cancer drug, has been used off-label to treat AMD (Nat. Biotechnol. 26, 867-875, 2008). But Genentech, a subsidiary of Basel-based Roche, never conducted clinical studies with Avastin in AMD, instead developing Lucentis, (an antigenbinding fragment derived from the same $\mathrm{mAb}$ as Avastin). Lucentis is approved by the US Food and Drug Administration for AMD and costs $\sim \$ 2,000$ per dose, whereas the price of Avastin reformulated for this indication is about \$50. The Comparison of AMD Treatments Trials (CATT) evaluated the outcomes in 1,208 people with neovascular AMD assigned to one of the treatments. "At one year, Lucentis and Avastin were equivalent for visual acuity at all time points when administered at the same dosing regimen," Daniel Martin, CATT study chair and chairman of the Cole Eye Institute at the Cleveland Clinic, told reporters. "In our study we clearly show equivalence between the two drugs." The study revealed no difference in the rates of death, myocardial infarction and stroke. "Regulators in certain countries will be forced to reconsider their policies that make it illegal to use drugs offlabel," Philip Rosenfeld of the Bascom Palmer Eye Institute of the University of Miami wrote in an editorial accompanying the publication of CATT in The New England Journal of Medicine. "The CATT data support the continued global use of intravitreal bevacizumab as an effective, lowcost alternative to ranibizumab." Mark Ratner

\section{French bioethics turmoil}

On May 31, the French National Assembly voted to maintain a prohibition on using human embryo and embryonic stem cells for research with some exemptions on 'medical progress' grounds - that is, diagnosis and drug testing. This second revision to the country's 1994 bioethics law, first revised in 2001, has triggered an intense debate. On February 15, the Assembly initially voted to maintain the existing prohibition. This was followed on April 8 by the Senate's support for embryonic research if done within a strict regulatory framework - a view backed by the special National Assembly bioethics commission. Ignoring its own commission's recommendations, the Assembly voted on May 25 to keep the prohibition with exemptions granted by the French Biomedicine Agency. Noël Mamère, Green MP commented during the debates, "a politics of status quo on a subject of this importance is like regression," whereas Alain Clayes, president of the Assembly's special bioethics commission, qualified the vote as a "missed opportunity." For scientists, the prospect of working under an exemption raises uncertainty and is thus particularly problematic to secure funding. Sabine Louët

\title{
Life sciences firms cheer unlocking of National Health Service
}

Although corporation tax reduction measures designed to stimulate investment into the UK economy announced this spring by the UK finance minister, George Osborne, received a warm reception from the life sciences industry, a raft of more targeted initiatives, particularly those that facilitated greater access to resources within the UK's National Health Service (NHS) are causing particular excitement.

"In the past, many small companies would identify the investment environment as their biggest single obstacle," explains UK Biolndustry Association chief executive, Nigel Gaymond, "but what investors are looking for is the opportunity to add value quickly." He believes that making it easier for UK-based companies to build working relationships with the NHS will indirectly stimulate investment in the bioscience sector. Earlier this year, Gaymond, welcomed the government's 'Plan for Growth,' an outline of the government's current economic policy objectives. The measures Osborne recently announced ensure the funding will be available for the parts of the plan with the potential to affect life sciences companies.

The new measures promise to streamline procurement, decrease bureaucracy, improve access to the NHS and promote a more efficient regulatory environment for clinical trials. For example, adoption of a mechanism for buying innovation and more efficient procurement policies is among the key elements of the plan intended to make it easier for small-to-medium-sized enterprises (SMEs) to access the procurement power of the NHS. The proposed mechanism builds on the existing Innovative Technology Adoption Procurement Programme. The program encourages NHS-wide adoption of high-impact innovative medical technologies that can improve the quality of patient care. Companies are invited to share information about a technology that could have an impact thereby improving SME access and a path to integration into the healthcare system for their products and services.

Another measure seeks to improve NHS performance for clinical trial approvals. Efficiency is at the core of the reform. The number of global and EU-wide clinical trials conducted in the UK has been declining since 2004-from 6\% in 2004 to $2 \%$ in 2008. According to the Department of Health, the number of trials being carried out in the UK in 2009 was 470 , down from 728 in 2008 . The new measures intend to ensure that reviews are streamlined and that precautions are proportionate to the real risks by appointing a new interim special health authority to oversee UK's medicines regulator, the Medicines and Healthcare products Regulatory Agency.

In addition, in 2010, the NHS created the Life Sciences Innovation Delivery Board to promote the use of cost-effective medicines and medical technologies, improve relationships between the life sciences sector and the NHS, and increase the attractiveness of the UK as a site for clinical trials and product development. To enable a coordinated approach to innovation in the reformed NHS, the current measures mean the Life Sciences Innovation Delivery Board will report to the NHS Commissioning Board in future.

"Its time to stop talking the UK industry down," Gaymond stresses, "and to make the most of the resources that we have." He believes that there has been a tendency to focus on negative events, such as the difficulty of finding finance from venture capital and the public markets and Pfizer's closure of its UK R\&D site in Sandwich, and thereby predict "doom and gloom" for the UK industry. According to Gaymond, "the government's moves to unlock the NHS and to encourage R\&D through the tax system, however, represents a renewed opportunity for UK industry to move forward with the help of government, rather than working against it." John Hodgson, Cambridge, UK 